\title{
O DIREITO SOCIAL À MORADIA COMO LIMITE À INCIDÊNCIA DO ITCD SOBRE IMÓVEIS DE FAMÍLIAS CARENTES
}

\section{THE SOCIAL RIGHT TO HOUSING AS A LIMIT ON ASSESSMENT OF THE ITCD TAX ON LOW-INCOME FAMILY RESIDENTIAL PROPERTIES}

\author{
Paulo Afonso Cavichioli Carmona ${ }^{1}$ \\ Fernanda Loures de Oliveira ${ }^{2}$
}

\section{Resumo}

Os direitos sociais foram capitulados como direitos fundamentais pela Constituição. Nesse sentido, torna-se importante delimitar certo conteúdo de eficácia jurídica aos seus preceitos. Especificamente quanto ao direito social à moradia, embora seja bastante controvertido seu conteúdo eficacial mínimo sob a ótica prestacional, não se apresentam as mesmas dificuldades quando o assunto é seu viés negativo, incluindo sua atuação como limite à tributação. Por isso, a partir de uma pesquisa qualitativa, e mediante a identificação e análise das legislações tributárias dos Estados e do Distrito Federal, pretende-se traçar a delimitação da eficácia jurídica do direito social à moradia, ao menos sob sua ótica negativa, no que concerne à incidência do imposto de transmissão causa mortis sobre imóveis de famílias carentes. Destacando-se as previsões locais mais condizentes com esse direito social, pretende-se dar a temática uma análise mais global, pautada no potencial do direito social à moradia como efetivo limite à tributação, mesmo para os casos em que não haja previsão legal específica. Nesse contexto, entende-se que o imposto sobre a transmissão causa mortis não deve incidir quando tendente à supressão do único imóvel pertencente à família carente, que atenda, em tese, os pressupostos para sua inclusão em política pública habitacional.

Palavras-Chave: Direito social à moradia. Limite à tributação. ITCD. Imóveis de famílias carentes. Política pública habitacional.

\begin{abstract}
Social rights are enshrined in the Brazilian Constitution as fundamental rights. In this light, it is important to delimit principles on the legal effectiveness of the underlying rights. While minimum enforceability of the right to housing is controversial from a social assistance standpoint, there is no such controversy as to its negative effects, including as a limit on taxation. With this in mind, we conducted a review of the pertinent literature and identified and analyzed the applicable tax legislation adopted by individual States and the Federal District, with a view to delimiting the legal effectiveness of the social right to housing, at least in respect of its negative impact on assessment of the Tax on the Transmission of Property Causa Mortis and Donations for low-income family residential properties. The objective was to identify those local

\footnotetext{
1 Doutor em Direito Urbanístico (PUC/SP). Professor do mestrado de Direito e de Arquitetura e Urbanismo do Centro Universitário de Brasília (UNICEUB) e dos cursos de pós-graduação da Fundação Escola Superior do Ministério Público do Distrito Federal e Territórios (FESMPDFT). Líder do Grupo de Pesquisa em Direito Público e Política Urbana (GPDPPU-Uniceub). E-mail: paulo.carmona@uniceub.br 2 Mestra em Direito e Políticas Públicas pelo Centro Universitário de Brasília. E-mail: floures.direito@gmail.com
} 
statutes most consistent with application of the social right in question and to provide a broader analysis centered on the potential of the fundamental right to housing to serve as an effective limit on taxation, including in the specific cases not covered by law. Based on our analysis, we argue that the causa mortis transmission tax should not be assessed where the respective obligation could affect the sole residential properties of low-income families that meet, in theory, at least, the criteria for inclusion in public housing policies.

Keywords: Social right to housing. Limit on taxation. ITCD tax. Low-income family residential property. Public housing policies.

\section{INTRODUÇÃO}

O presente artigo tem como finalidade demonstrar que o direito social à moradia pode ser encarado como instrumento destinado a oferecer limites à tributação sobre a propriedade imóvel. Restringe-se, porém, a analisar o papel desse limite constitucional em face do imposto sobre a transmissão causa mortis, embora não se negue a possibilidade de extensão dos argumentos apresentados para outras espécies tributárias, não cogitadas durante a elaboração deste estudo.

Utiliza-se como metodologia a pesquisa qualitativa, primando-se pela análise das fontes de doutrina pertinentes a cada matéria objeto de estudo, além do necessário subsídio normativo. Toma-se como marco teórico a ideia de Luís Eduardo Schoueri, expressa em seu trabalho "Tributação e liberdade", de acordo com a qual não apenas as imunidades expressas servem como limites à tributação, mas uma série de outros valores, consignados nos direitos fundamentais.

Inicia-se o estudo pelo exame da eficácia jurídica dos direitos sociais e, em especial, do direito à moradia. Parte-se, então, para a análise da relação tributação vs. direitos fundamentais, concluindo-se que, embora os tributos sejam necessários para a consecução das finalidades do Estado, os direitos fundamentais - e, especialmente, o direito à moradia podem servir como limites à pretensão arrecadatória estatal. Por fim, parte-se para a análise do imposto sobre a transmissão causa mortis, bem como para o papel do direito social à moradia como barreira à incidência do mencionado imposto.

A importância do estudo é manifesta, tanto sob o ponto de vista teórico, quanto sob a ótica fática. É imprescindível a delimitação da eficácia jurídica do direito social à moradia, ao menos sob sua ótica negativa, para o desenvolvimento da ciência jurídica. Do mesmo modo, a análise do direito à moradia como limite à tributação é indispensável à afirmação de um sistema 
tributário mais justo, que leve em conta as necessidades básicas das pessoas em situação de vulnerabilidade social.

\section{A EFICÁCIA DO DIREITO SOCIAL À MORADIA}

As normas jurídicas submetem-se a três tipos distintos e independentes de valoração, relacionados à justiça, à validade e à eficácia. O problema da justiça diz respeito à correspondência ou não da disposição normativa aos valores que informam o ordenamento. 0 problema da validade relaciona-se à existência da norma no mundo jurídico. E o problema da eficácia relaciona-se à questão de se a norma é ou não cumprida e, em caso de descumprimento, se é imposta por meios coercitivos (BOBBIO, 2001, pp. 45-47).

Uma norma é socialmente eficaz quando é executada ou aplicada no seio social (REALE, 2002, p. 113). No entanto, a eficácia como gênero não se restringe ao sentido da eficácia social ou efetividade, abrangendo também a eficácia jurídica, entendida como a aptidão da norma de produzir, em maior ou menor medida, efeitos jurídicos. A eficácia jurídica relaciona-se aos conceitos de aplicabilidade, exigibilidade ou executoriedade do comando normativo (SILVA, 1998, pp. 65-66) e é nesse sentido que se utiliza o termo eficácia para os fins deste trabalho.

Com efeito, o art. 5ํ, § 1ํ, da Constituição Federal estabelece a determinação de que as normas definidoras de direitos e garantias fundamentais tenham aplicação imediata. Nessa linha, à primeira vista, todos os direitos fundamentais constantes do extenso rol constitucional seriam dotados de aplicabilidade plena e imediata, com amplo grau de eficácia jurídica. Entretanto, não é isso o que se nota na prática constitucional, pois a própria Constituição condiciona a aplicabilidade de certas normas constitucionais à necessidade de legislação ulterior. É o que ocorre em relação aos direitos sociais (SILVA, 2005, p. 180), os quais podem ser conceituados como os destinados a proporcionar condições fáticas para o exercício dos demais direitos às pessoas em situação de vulnerabilidade, abrangendo direitos prestacionais - como saúde, educação, moradia, seguridade, entre outros; e direitos negativos - como limitação da jornada laboral, garantia do salário mínimo, etc. (GOTTI, 2012, pp. 44-46).

Nesse sentido, erigem-se como empecilhos à efetiva aplicação dos direitos sociais, incluindo sua tutela judicial, a vagueza dos textos que os estabelecem e a omissão quanto a uma prática institucional de interpretação dos instrumentos jurídicos de regência, ante a ausência de mecanismos adequados de aplicação. Além do fato de que parte da doutrina os 
considera como direitos programáticos, que não ensejam a submissão do Estado a um sistema de implementação de tipo contencioso (ABRAMOVICH; COURTIS, 2002, pp. 66-67).

Por outro lado, não cabe interpretar os direitos sociais como se fossem simples cartas de intenções, ao menos não em terras brasileiras. Isso porque a Constituição Federal os trata como autênticos direitos. Não se pode, pois, confundir os direitos sociais definidos constitucionalmente com o direcionamento da política social indicada na Constituição (BARROSO, 1995, p. 86). É preciso, dessarte, delimitar certo conteúdo de eficácia jurídica aos direitos sociais.

Decerto, nenhum direito - seja civil, político, cultural, econômico, social, difuso ou coletivo - pode ser executado sem apoio e financiamento público (HOLMES; SUNSTEIN, 1999, p. 15). Nem por isso o dispêndio econômico dos direitos sociais deixa de ser especialmente relevante, quando comparado ao dos demais direitos fundamentais. Se, de fato, o exercício de direitos civis e políticos, como o direito de liberdade, requer "gastos com a manutenção das instituições políticas, judiciais e de segurança", tais gastos institucionais também abrangem os direitos sociais. A manutenção de instituições judiciárias, por exemplo, é necessária à efetivação de qualquer direito, incluindo os sociais, mas os direitos sociais, além desse gasto, também demandam o dispêndio de recursos para a compra dos bens e a manutenção dos serviços indispensáveis à sua execução, como, no que diz respeito ao clássico direito à saúde, o dispêndio com a compra de medicamentos. Por isso há diferença na comparação entre a alocação de recursos públicos necessária para a consecução de direitos sociais, que demandam mais dinheiro (SILVA, 2008, p. 593).

Portanto é difícil determinar o conteúdo eficacial mínimo, sob o aspecto jurídico, dos direitos sociais como um todo. Essa análise, sob a perspectiva prestacional, deve levar em conta a possibilidade de universalização da execução do direito, em prol de todos aqueles que necessitem de sua consecução e se encontrem nas mesmas condições (SOUZA NETO, 2008, pp. 540-541), já que, sob a égide do princípio da isonomia, não se admite a elaboração de critérios injustificados de discrímen (MELLO, 2001, p. 39-41). Assim, por exemplo, no que diz respeito ao direito ao trabalho, é difícil justificar um suposto direito do desempregado a condenar a Administração Pública a lhe dar um emprego, pois tal medida não é passível de universalização (SOUZA NETO, 2008, pp. 540).

Com tais ponderações não se quer dar novas vestes à combatida ideia da reserva do possível como via destinada a reforçar a primazia do aspecto financeiro ou das disposições orçamentárias sobre os direitos fundamentais (CORTI, 2011, pp. 163-164). Quer-se apenas dizer 
que a avaliação objetiva sobre a capacidade econômico-financeira da pessoa estatal (BRASIL. STF, 2004), em relação à efetivação de um direito social, deve necessariamente levar em conta a perspectiva da viabilidade de universalização, em nome do princípio da isonomia.

No entanto, semelhante dificuldade na execução não se apresenta tão forte quando o assunto é a faceta negativa dos direitos sociais, isto é, a necessidade de que o Estado, ao contrário de prover, simplesmente se abstenha de subtrair do indivíduo - observados certos pressupostos - os direitos sociais que já possui (SARLET, 2015, pp. 354-355):

Apesar do exposto, seguimos convictos - como, de resto, esperamos demonstrar nas páginas que seguem - que para o efeito de se admitir a imediata aplicação pelos órgãos do Poder Judiciário, o corretamente apontado "fator custo" de todos os direitos fundamentais, nunca constituiu um elemento impeditivo da efetivação pela via jurisdicional (no sentido pelo menos da negativa da prestação jurisdicional) quando em causa direitos subjetivos de conteúdo "negativo". É justamente neste sentido que deve ser tomada a referida "neutralidade" econômicofinanceira dos direitos de defesa, visto que a sua eficácia jurídica (ou seja, a eficácia dos direitos fundamentais na condição de direitos negativos) e a efetividade naquilo que depende da possibilidade de implementação jurisdicional não tem sido colocada na dependência da sua possível relevância econômica.

No que tange ao direito à moradia, típico direito de caráter social, encontra-se previsto

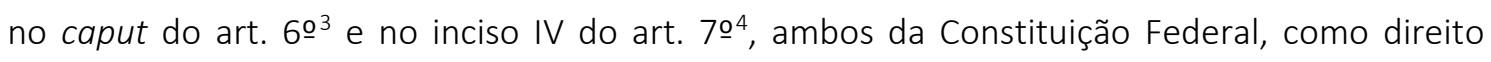
social de caráter fundamental; e no inciso IX do art. $23^{5}$, também da Carta Constitucional, como competência material comum, a ser promovido por todos os entes federativos. A par da previsão constitucional, na seara internacional, o direito social à moradia foi previsto no art. 11 do Pacto Internacional sobre Direitos Econômicos, Sociais e Culturais, promulgado, no Brasil, pelo Decreto 591 de 6 de julho de 1992. Além de ser expressamente reconhecido em uma infinidade de diferentes textos da ONU (CARMONA, 2015, p. 270).

A eficácia jurídica do direito à moradia submete-se aos mesmos meandros referidos para os direitos sociais como gênero. Embora seja instigante a discussão sobre o conteúdo

\footnotetext{
${ }^{3}$ Art. 6o São direitos sociais a educação, a saúde, a alimentação, o trabalho, a moradia, o transporte, o lazer, a segurança, a previdência social, a proteção à maternidade e à infância, a assistência aos desamparados, na forma desta Constituição.

${ }^{4}$ Art. 70 São direitos dos trabalhadores urbanos e rurais, além de outros que visem à melhoria de sua condição social: IV - salário mínimo, fixado em lei, nacionalmente unificado, capaz de atender a suas necessidades vitais básicas e às de sua família com moradia, alimentação, educação, saúde, lazer, vestuário, higiene, transporte e previdência social, com reajustes periódicos que the preservem o poder aquisitivo, sendo vedada sua vinculação para qualquer fim;

5 Art. 23. É competência comum da União, dos Estados, do Distrito Federal e dos Municípios: IX promover programas de construção de moradias e a melhoria das condições habitacionais e de saneamento básico;
} 
eficacial mínimo do direito à moradia - e dos direitos sociais em geral -, sob a ótica prestacional, o que se pretende discutir nas linhas seguintes é a questão do viés negativo do direito à moradia, confrontando-o com a tributação.

\section{O DIREITO À MORADIA COMO LIMITE À TRIBUTAÇÃO}

Os estados contemporâneos adotam largamente o modelo de estado fiscal, por meio de suas Constituições. De acordo com esse modelo, as necessidades financeiras estatais devem necessariamente ser atendidas por meio dos tributos (NABAIS, 1998, pp. 191-192 e 196):

A "estadualidade fiscal" significa assim uma separação fundamental entre estado e economia e a consequente sustentação financeira daquele através da sua participação nas receitas da economia produtiva pela via do imposto. Só essa separação permite que o estado e a economia actuem segundo critérios próprios ou autônomos. O estado orienta-se pelo interesse geral ou comunitário da realização da justiça [...]. A economia, por seu turno, guia-se pelo critério do lucro [...].

Por conseguinte, é evidente a importância dos tributos, mormente, dos impostos, por possuir a necessária flexibilidade para fazer frente às crescentes necessidades financeiras do Estado Social, bem como por produzir relevante efeito de redistribuição de renda. Exatamente por tais fundamentos, afirma-se que o tributo - e mais concretamente o imposto - é pressuposto funcional do Estado Social, no sentido de que este último dele necessita para poder efetivar-se (ESTEVAN, 2002, p. 54). Quando se pensa o Estado Social - o qual tem por escopo garantir a liberdade de todos -, o tributo desponta como o instrumento de concretização da liberdade, preço que toda a sociedade paga para que o Estado possa garantir liberdade às pessoas em situação de vulnerabilidade (SCHOUERI, 2006, pp. 456-462).

A função básica do Estado é, assim, a garantia dos direitos fundamentais. Para tanto, porém, o custo da manutenção estatal deve ser dividido de modo justo por todos os cidadãos. Nessa equação, se, de uma parte, o Estado necessita da receita tributária para ter condições econômicas suficientes à garantia dos direitos fundamentais, de outra, "frequentemente a cobrança de tributos pelo Estado restringe os recursos necessários para suprir necessidades fundamentais do indivíduo" (MEIRA, 2012, pp. 231-232 e 234).

Não se nega, assim, o caráter fundamental dos tributos para a afirmação dos direitos fundamentais, sendo mesmo o "preço" que se paga por sua afirmação. Considera-se, porém, que a sociedade coeva passa a compreender que, por vezes, o preço que se paga para que o Estado atinja o desiderato coletivo é alto demais, ao passo que o resultado obtido é ainda pífio. 
Por isso ganha corpo a ideia de limite à atuação do Estado e de restrição à tributação (SCHOUERI, 2006, pp. 465-467):

A tributação é, novamente, um instrumento para que se atinjam os fins do Estado. Mas esses não são diversos daqueles buscados pela sociedade civil; quando esta assume dimensão pública, encontra-se limitação na tributação.

Assim, já num primeiro momento, encontram-se as imunidades constitucionais, que concretizam espaços que não podem ser atingidos pela tributação. O "preço" não pode ser tão alto a ponto de sacrificar a própria liberdade protegida pelo constituinte. [...].

A ideia de limitação no preço da liberdade vai além das imunidades expressas, atingindo uma série de outros valores, consignados nos direitos humanos. É assim, por exemplo, que se justifica a imunidade do mínimo vital, que se concretiza no respeito à capacidade contributiva: há limites no que se transfere ao Estado. Não se justifica uma transferência excessiva, por parte do Estado, se com aqueles recursos não se acrescentará parcela de liberdade coletiva, enquanto, ao mesmo tempo, tais recursos, nas mãos da sociedade civil, revelam-se mais aptos a promover a inclusão social.

A ideia mesma de Estado Fiscal se assenta em limites, tanto máximos quanto mínimos. No entanto, o limite máximo é o que mais preocupa, cotidianamente, o qual se impõe frente a um estado que, tendo atingido tal monta, continua a crescer, embora ofereça um arsenal protetivo insuficiente (NABAIS, 1998, pp. 216-218).

De fato, a tributação é garantia à consecução dos direitos fundamentais, mas os direitos fundamentais também representam limites à tributação. Eis as duas principais relações existentes entre os institutos. Nessa seara, é imperioso averiguar qual a melhor orientação para o Estado: "tributar para garantir, ou não tributar para não restringir" (MEIRA, 2012, p. 235), o que demanda exame prático.

A presença de um mínimo de direitos fundamentais do homem é o que completa materialmente o conceito de Estado de Direito (VILANOVA, 1978, p. 78). Entre os direitos fundamentais constitucionalmente previstos, em solo pátrio, encontra-se o direito à moradia. Nesse sentido, resta claro que o direito à moradia é um limite à tributação.

Bem se sabe ser objeto de severas críticas o fato de que a carga tributária brasileira exerce pressão elevada sobre o consumo, sendo branda sob os aspectos "bens" e "rendas". De fato, levando-se em consideração o ano de 2010, calcula-se que, do total da carga tributária pátria, a tributação sobre o patrimônio restrinja-se a 3,52\%, ao passo que, nos países integrantes da Organização para a Cooperação e Desenvolvimento Econômico - OCDE, o percentual seja de 5,4\% (GASSEN; D’ARAÚJO; PAULINO, 2013, p. 215). No entanto, a carga tributária não alcança todos os contribuintes de igual modo, motivo pelo qual é possível 
considerar que certo imposto é brando em relação a determinado contribuinte, mas excessivamente oneroso em relação a outro, vulnerando seus direitos fundamentais. É, pois, imprescindível a observância à capacidade contributiva, sob a ótica da desigualdade econômica dos indivíduos e do primado do justo distributivo (OLIVEIRA; BORGES, 2016, p. 184).

Nessa perspectiva, considerando-se a afirmação de que o direito à moradia constitui limite à pressão fiscal sobre o patrimônio imobiliário, resta apenas saber em quais hipóteses a carga tributária deve ceder em prol do exercício desse direito social de caráter fundamental. É o que se passa a analisar no item seguinte, especificamente sob a ótica do imposto sobre a transmissão causa mortis de quaisquer bens ou direitos.

\section{O IMPOSTO DE TRANSMISSÃO CAUSA MORTIS SOBRE IMÓVEL DE FAMÍLIA DE BAIXA RENDA}

O ITCD ou imposto sobre a transmissão causa mortis e doação, de quaisquer bens ou direitos, é tributo constitucionalmente previsto como de competência dos Estados e do Distrito Federal ${ }^{6}$. Trata-se de exação cuja hipótese normativa é composta de institutos de direito privado. Nesse sentido, "a estrutura do negócio jurídico integra o antecedente" normativo, motivo pelo qual se diz que, ao selecionar o fato passível de tributação pelo ITCD, o constituinte fez uso de um "tipo estrutural" (CARVALHO, 2013, pp. 484-485).

Antes, porém, de analisar o instituto de direito privado adjacente à exação sobre a herança - cujos delineamentos devem ser respeitados, já que a lei tributária não pode alterar definições de direito privado (art. 110 do Código Tributário Nacional) - vale tecer breves comentários sobre a regra-matriz de incidência do imposto.

Com efeito, conforme Carvalho (2013, pp. 612-613), a "regra-matriz" ou "normapadrão" de incidência tributária consiste em um modelo destinado a estruturar a interpretação das normas tributárias em sentido estrito, isto é, aquelas cujo objeto é o "núcleo do impacto jurídico da exação". O modelo é composto de hipótese de incidência e consequente normativo. $\mathrm{Na}$ hipótese, compreendem-se os critérios material (comportamento humano), temporal (determinação de tempo) e espacial (determinação de lugar). Já o consequente é composto de critérios pessoal (sujeito ativo e passivo que se unem em uma relação obrigacional tributária) e quantitativo (base de cálculo e alíquota).

\footnotetext{
${ }^{6}$ Art. 155. Compete aos Estados e ao Distrito Federal instituir impostos sobre: I - transmissão causa mortis e doação, de quaisquer bens ou direitos;
} 
No caso do imposto sobre a herança, o critério material consiste no verbo "transmitir" quaisquer bens ou direitos (complemento), em virtude do falecimento da pessoa física, com o que se dá a abertura da sucessão, regulada pelo Título I do Código Civil Brasileiro. Também é legítima a incidência no caso de morte presumida (Súmula 331 do Supremo Tribunal Federal). Nas transmissões causa mortis ocorrem tantos fatos geradores distintos quanto sejam os herdeiros ou legatários (art. 35, parágrafo único, do Código Tributário Nacional). Vale mencionar que o vocábulo transmissão, no âmbito do direito civil, pressupõe a transferência da titularidade dos bens ou direitos, de modo que não haverá incidência do imposto sobre a parte integrante da meação do cônjuge supérstite, uma vez que tal parte já Ihe pertencia anteriormente ao fator morte.

Por sua vez, o critério temporal é determinado com o evento morte, conforme definido pela lei civil. Nos termos do art. 1.784 do Código Civil, que enuncia o princípio de saisine, aberta a sucessão, a herança transmite-se, desde logo, aos herdeiros legítimos e testamentários.

De outra parte, o critério espacial está previsto no § 1의 do art. 155 da Constituição Federal. No que tange aos bens imóveis e respectivos direitos, o imposto é devido ao Estado da situação do bem, ou ao Distrito Federal (inciso I). Quanto aos bens móveis, títulos e créditos, compete ao Estado onde se processar o inventário ou arrolamento, ou tiver domicílio o doador, ou ao Distrito Federal (inciso II). Por outro lado, caberá à lei complementar regular a competência para a instituição do ITCD no caso de o de cujus possuir bens, ser residente ou domiciliado ou ter seu inventário processado no exterior (inciso III, alínea "b").

Por seu turno, no que tange ao consequente normativo, o critério pessoal é composto de sujeito ativo e sujeito passivo. O sujeito ativo, credor do tributo, é o Estado ou o Distrito Federal, nos termos do art. 155, inciso I, da Constituição Federal. Já o sujeito passivo é a pessoa da qual se exige o adimplemento da obrigação fiscal, isto é, o(s) herdeiro(s) e/ou legatário(s) do falecido ou cessionário(s) da herança, desde que aceitem a herança, conforme a legislação civil.

Por sua vez, o critério quantitativo é composto, como mencionado, de base de cálculo e alíquota. A base de cálculo é determinada pelo art. 38 do Código Tributário Nacional, como o valor venal dos bens ou direitos transmitidos. No caso de inventário judicial, o imposto não é exigível antes da homologação do respectivo cálculo (Súmula 114 do Supremo Tribunal Federal). Quanto ao percentual incidente sobre a base de cálculo, nos termos do inciso IV do $\S$ 1o do art. 155 da Constituição, terá suas alíquotas máximas fixadas pelo Senado Federal. Nesse sentido, foi fixada como máxima a alíquota de 8\% (Resolução 9 de 1992).

No que concerne à regulamentação local, segue quadro comparando suas distinções: 
Tabela 1: ITCD dos Estados e do Distrito Federal e direito social à moradia

\begin{tabular}{|c|c|c|c|}
\hline $\begin{array}{l}\text { Unidade } \\
\text { Federativa }\end{array}$ & Ato Normativo & $\begin{array}{l}\text { Alíquota } \\
\text { Máxima }\end{array}$ & $\begin{array}{l}\text { Previsão para famílias carentes baseada no } \\
\text { direito à moradia }\end{array}$ \\
\hline Acre & $\begin{array}{l}\text { Lei complementar } \\
271 \text { de } 27 \text { de } \\
\text { dezembro de } 2013 \text {. }\end{array}$ & $4 \%$ & $\begin{array}{l}\text { Art. 8․ Ficam isentas do ITCMD: I - a } \\
\text { transmissão causa mortis: a) dos imóveis } \\
\text { urbanos, desde que o valor destes bens não } \\
\text { ultrapasse R\$ 203.400,00 (duzentos e três } \\
\text { mil e quatrocentos reais); b) dos imóveis } \\
\text { rurais, desde que o valor destes bens não } \\
\text { ultrapasse R\$ } 135.600,00 \text { (cento e trinta e } \\
\text { cinco mil e seiscentos reais); }\end{array}$ \\
\hline Alagoas & $\begin{array}{l}\text { Lei } 5.077 \text { de } 12 \text { de } \\
\text { junho de } 1989 .\end{array}$ & $4 \%$ & - \\
\hline Amapá & $\begin{array}{l}\text { Lei } 400 \text { de } 22 \text { de } \\
\text { dezembro de } 1997 .\end{array}$ & $4 \%$ & $\begin{array}{l}\text { Art. } 76 \text {. Ficam isentas do imposto: II - as } \\
\text { transmissões hereditárias de prédio de } \\
\text { residência que constitua o único bem de } \\
\text { espólio, cujo valor não ultrapasse } 20.000 \\
\text { UPF/AP (vinte mil Unidades de Padrão Fiscal } \\
\text { do Estado do Amapá), desde que à sucessão } \\
\text { concorra apenas o cônjuge ou filhos do "de } \\
\text { cujus"; III - as transmissões, por sucessão, } \\
\text { de propriedade ou domínio útil de bem } \\
\text { imóvel e de direitos reais sobre imóveis } \\
\text { como originário dos quilombos, assim } \\
\text { definidos por resolução do Conselho de } \\
\text { Cultura Estadual, desde que à sucessão } \\
\text { concorram apenas o cônjuge ou filhos do de } \\
\text { cujus. }\end{array}$ \\
\hline Amazonas & $\begin{array}{c}\text { Lei complementar } 19 \\
\text { de } 29 \text { de dezembro } \\
\text { de } 1997 .\end{array}$ & $2 \%$ & $\begin{array}{l}\text { Art. 118. São isentos do imposto: III - } \\
\text { transmissão causa mortis de: a) imóvel, } \\
\text { rural ou urbano, cujo valor não ultrapasse } \\
\text { R\$ } 100.000,00 \text { (cem mil reais) e o(s) } \\
\text { beneficiado(s) não possua(m) outro imóvel. }\end{array}$ \\
\hline Bahia & $\begin{array}{c}\text { Lei } 4.826 \text { de } 27 \text { de } \\
\text { janeiro de } 1989 .\end{array}$ & $8 \%$ & $\begin{array}{l}\text { Art. 4o. Ficam isentas do imposto: I - as } \\
\text { transmissões, por sucessão, de prédio de } \\
\text { residência a cônjuge e filhos do servidor } \\
\text { público estadual, falecido, quando esta seja } \\
\text { a única propriedade do espólio, desde que } \\
\text { comprovem nãom, naírem, } \\
\text { individualmente, em sua totalidade outro } \\
\text { imóvel; II - as transmissões hereditárias de } \\
\text { prédio de residência que constitua o único } \\
\text { bem do espólio, cujo valor do imóvel seja } \\
\text { igual ou inferior a R\$170.000,00 (cento e } \\
\text { setenta mil reais), desde que à sucessão } \\
\text { concorram apenas o cônjuge ou filhos do } \\
\text { "de cujus" e que fique comprovado não } \\
\text { possuírem outro imóvel; }\end{array}$ \\
\hline
\end{tabular}




\begin{tabular}{|c|c|c|c|}
\hline Ceará & $\begin{array}{l}\text { Lei } 15.812 \text { de } 20 \text { de } \\
\text { julho de } 2015 .\end{array}$ & $8 \%$ & $\begin{array}{l}\text { Art. 8o. São isentas do ITCD: I - a } \\
\text { transmissão causa mortis: a) do patrimônio } \\
\text { transmitido pelo de cujus ao herdeiro ou } \\
\text { legatário cujo valor do respectivo quinhão } \\
\text { ou legado não ultrapasse } 7.000 \text { (sete mil) } \\
\text { Ufirces; III - a transmissão causa mortis de } \\
\text { imóvel rural de área não superior a } 3 \text { (três) } \\
\text { módulos rurais, assim caracterizados na } \\
\text { forma de legislação pertinente, desde que } \\
\text { feitas a quem não seja proprietário de } \\
\text { imóvel de qualquer natureza. }\end{array}$ \\
\hline $\begin{array}{l}\text { Distrito } \\
\text { Federal }\end{array}$ & $\begin{array}{l}\text { Lei } 3.804 \text { de } 08 \text { de } \\
\text { fevereiro de } 2006 \text {. }\end{array}$ & $6 \%$ & $\begin{array}{l}\text { Art. 6o. É concedida isenção do ITCD: II - ao } \\
\text { herdeiro ou legatário, na transmissão causa } \\
\text { mortis, desde que o patrimônio transmitido } \\
\text { pelo de cujus não ultrapasse o valor de R\$ } \\
114.999,98 \text { (cento e catorze mil, } \\
\text { novecentos e noventa e nove reais e } \\
\text { noventa e oito centavos). § 3o. A isenção } \\
\text { prevista no inciso II refere-se ao patrimônio } \\
\text { total transmitido pelo de cujus ao herdeiro } \\
\text { ou ao legatário. }\end{array}$ \\
\hline $\begin{array}{l}\text { Espírito } \\
\text { Santo }\end{array}$ & $\begin{array}{l}\text { Lei } 10.011 \text { de } 20 \text { de } \\
\text { maio de } 2013 .\end{array}$ & $4 \%$ & $\begin{array}{l}\text { Art. 7o. Ficam isentas do imposto: I - a } \\
\text { transmissão causa mortis de: a) imóvel } \\
\text { destinado exclusivamente à moradia do } \\
\text { herdeiro ou legatário, até o limite de } \\
\text { duzentos mil Valores de Referência do } \\
\text { Tesouro Estadual (VRTEs) e desde que não } \\
\text { possua outro bem imóvel, observado o } \\
\text { disposto no } § 10 ; \text { b) imóvel cujo valor não } \\
\text { ultrapassar vinte mil VRTEs, desde que seja } \\
\text { o único transmitido; c) imóvel rural com } \\
\text { área não superior a vinte e cinco hectares, } \\
\text { de cuja exploração do solo dependa o } \\
\text { sustento da família do herdeiro ou do } \\
\text { cônjuge supérstite a que tenha cabido por } \\
\text { partilha, desde que outro não possua; } § 10 . \\
\text { Nas hipóteses previstas no inciso I, "a" e } \\
\text { "d", caso o valor total da transmissão } \\
\text { ultrapassar o limite ali fixado, o imposto } \\
\text { será calculado apenas sobre a parte } \\
\text { excedente. }\end{array}$ \\
\hline Goiás & $\begin{array}{l}\text { Lei } 11.651 \text { de } 26 \text { de } \\
\text { dezembro de } 1991 \text {, e } \\
\text { Lei } 19.021 \text { de } 30 \text { de } \\
\text { setembro de } 2015 .\end{array}$ & $8 \%$ & $\begin{array}{l}\text { Art. 79. São isentos do pagamento do ITCD: } \\
\text { I - o herdeiro, o legatário ou o donatário } \\
\text { que houver sido aquinhoado com um bem } \\
\text { imóvel: a) urbano, edificado, destinado à } \\
\text { moradia própria ou de sua família, desde } \\
\text { que, cumulativamente: } 1 \text {. o beneficiário não } \\
\text { possua outro imóvel residencial; } 2 \text {. a } \\
\text { doação, a legação ou a participação na }\end{array}$ \\
\hline
\end{tabular}




\begin{tabular}{|c|c|c|c|}
\hline & & & $\begin{array}{l}\text { herança limite-se a esse bem; } 3 \text {. o valor do } \\
\text { bem seja igual ou inferior a } \mathrm{R} \$ 25.000,00 \\
\text { (vinte e cinco mil reais); b) rural, cuja área } \\
\text { não ultrapasse o módulo da região; }\end{array}$ \\
\hline Maranhão & $\begin{array}{l}\text { Lei } 7.799 \text { de } 19 \text { de } \\
\text { dezembro de } 2002 \text {, e } \\
\text { Lei } 10.283 \text { de } 17 \text { de } \\
\text { julho de } 2015 .\end{array}$ & $7 \%$ & $\begin{array}{l}\text { Art. 107-A. Fica isenta do imposto a } \\
\text { transmissão: I - de bem imóvel urbano, } \\
\text { desde que constitua o único bem a ser } \\
\text { partilhado e que a sua avaliação seja igual } \\
\text { ou inferior a trinta e duas vezes o valor do } \\
\text { salário-mínimo vigente no Estado à época } \\
\text { da transmissão; II - de bem imóvel rural, } \\
\text { desde que constitua o único bem a ser } \\
\text { partilhado e que a sua avaliação seja igual } \\
\text { ou inferior a vinte e uma vezes o valor do } \\
\text { salário mínimo vigente no Estado à época } \\
\text { da transmissão; }\end{array}$ \\
\hline Mato Grosso & $\begin{array}{l}\text { Lei } 7.850 \text { de } 18 \text { de } \\
\text { dezembro de } 2002 \text {, e } \\
\text { Lei } 10.488 \text { de } 29 \text { de } \\
\text { dezembro de } 2016 .\end{array}$ & $8 \%$ & $\begin{array}{l}\text { Art. 6o. Fica isenta do imposto: I - a } \\
\text { transmissão causa mortis: a) de patrimônio } \\
\text { cujo valor total transferido a cada } \\
\text { beneficiário não ultrapassar a } 1.500 \text { (mil e } \\
\text { quinhentas) Unidades Padrão Fiscal do } \\
\text { Estado de Mato Grosso-UPF/MT; }\end{array}$ \\
\hline $\begin{array}{l}\text { Mato Grosso } \\
\text { do Sul }\end{array}$ & $\begin{array}{l}\text { Lei } 1.810 \text { de } 22 \text { de } \\
\text { dezembro de } 1997 .\end{array}$ & $6 \%$ & $\begin{array}{l}\text { Art. 126. São isentas do ITCD: II - as } \\
\text { transmissões causa mortis de bem imóvel: } \\
\text { a) sendo rural, sua área não ultrapasse o } \\
\text { módulo da região e seja destinado aos } \\
\text { herdeiros; b) sendo urbano, apresente } \\
\text { construção residencial de padrão popular } \\
\text { ou inferior e seja utilizada como habitação } \\
\text { dos herdeiros; III - as transmissões causa } \\
\text { mortis de bens e direitos cujos valores não } \\
\text { ultrapassem R\$ 50.000,00 (cinquenta mil } \\
\text { reais). § } 4 \text { o. O limite previsto nos incisos I e } \\
\text { III do caput deste artigo aplica-se em } \\
\text { relação a cada doação ou transmissão causa } \\
\text { mortis, independentemente de quantos } \\
\text { forem os herdeiros, os legatários ou os } \\
\text { donatários. }\end{array}$ \\
\hline Minas Gerais & $\begin{array}{l}\text { Lei } 14.941 \text { de } 29 \text { de } \\
\text { dezembro } 2003 .\end{array}$ & $5 \%$ & $\begin{array}{l}\text { Art. 30. Fica isenta do imposto: I - a } \\
\text { transmissão causa mortis de: a) imóvel } \\
\text { residencial com valor total de até } 40.000 \\
\text { Ufemgs (quarenta mil Unidades Fiscais do } \\
\text { Estado de Minas Gerais), desde que seja o } \\
\text { único bem imóvel de monte partilhável cujo } \\
\text { valor total não exceda } 48.000 \text { (quarenta e } \\
\text { oito mil) Ufemgs, excetuando-se os bens } \\
\text { descritos na alínea "c" deste inciso; c) roupa } \\
\text { e utensílio agrícola de uso manual, bem } \\
\text { como de móvel e aparelho de uso }\end{array}$ \\
\hline
\end{tabular}




\begin{tabular}{|c|c|c|c|}
\hline & & & $\begin{array}{l}\text { doméstico que guarneçam as residências } \\
\text { familiares; }\end{array}$ \\
\hline Pará & $\begin{array}{l}\text { Lei } 5.529 \text { de } 05 \text { de } \\
\text { janeiro de } 1989 .\end{array}$ & $4 \%$ & $\begin{array}{l}\text { Art. } 3^{\circ} \text {. São isentos do imposto: I - a } \\
\text { aquisição, por transmissão "Causa Mortis", } \\
\text { de imóvel destinado exclusivamente à } \\
\text { morada do cônjuge supérstite, herdeiros ou } \\
\text { legatários, desde que o "de cujus", o } \\
\text { cônjuge supérstite, o herdeiro e o legatário } \\
\text { não possuam outro imóvel; II - a aquisição, } \\
\text { por transmissão "Causa Mortis", de imóvel } \\
\text { rural com área não superior a vinte e cinco } \\
\text { hectares, de cuja exploração do solo } \\
\text { dependa o sustento da família dos } \\
\text { herdeiros ou do cônjuge supérstite e que } \\
\text { tenha cabido por partilha, desde que outro } \\
\text { não possua; }\end{array}$ \\
\hline Paraíba & $\begin{array}{l}\text { Lei } 5.123 \text { de } 27 \text { de } \\
\text { janeiro de } 1989 \text {, e Lei } \\
10.507 \text { de } 18 \text { de } \\
\text { setembro de } 2015 .\end{array}$ & $8 \%$ & $\begin{array}{l}\text { Art. 5o. São isentos do imposto: I - a } \\
\text { transmissão "causa mortis" e a doação de } \\
\text { bens quando o herdeiro, o legatário ou o } \\
\text { donatário for servidor público ou } \\
\text { autárquico, ativo ou inativo, deste Estado, } \\
\text { ou ex-combatente da Força Expedicionária } \\
\text { Brasileira, desde que o beneficiário não } \\
\text { possua outro imóvel e o bem assim } \\
\text { adquirido se destine à sua residência; II - a } \\
\text { transmissão "causa mortis" ou doação de } \\
\text { imóvel rural cuja área não exceda à } \\
\text { legalmente fixada para o módulo rural da } \\
\text { região, quando o adquirente não possuir } \\
\text { outro imóvel; III - a transmissão "causa } \\
\text { mortis" e a doação de bens móveis sem } \\
\text { expressão econômica, na forma do } \\
\text { regulamento; } V \text { - a transmissão "causa } \\
\text { mortis" de imóvel residencial destinado à } \\
\text { moradia do cônjuge supérstite ou herdeiro, } \\
\text { desde que o beneficiário não possua outro } \\
\text { imóvel e a transmissão assim efetivada se } \\
\text { restrinja a esse bem. } § \text { 1o As isenções } \\
\text { previstas nos incisos I e } V \text { deste artigo } \\
\text { alcançam o patrimônio deixado pelo "de } \\
\text { cujus" ao herdeiro ou legatário desde que } \\
\text { valor do respectivo quinhão ou legado não } \\
\text { ultrapasse R\$ } 84.000,00 \text { (oitenta e quatro } \\
\text { mil reais). }\end{array}$ \\
\hline Paraná & $\begin{array}{l}\text { Lei } 18.573 \text { de } 30 \text { de } \\
\text { setembro de } 2015 .\end{array}$ & $4 \%$ & $\begin{array}{l}\text { Art. 11. É isenta do pagamento do imposto: } \\
\text { I- a transmissão causa mortis: a) de único } \\
\text { imóvel, por beneficiário, destinado } \\
\text { exclusivamente à moradia do cônjuge } \\
\text { sobrevivente ou de herdeiro, que outro não }\end{array}$ \\
\hline
\end{tabular}




\begin{tabular}{|c|c|c|c|}
\hline & & & $\begin{array}{l}\text { possua; d) a aquisição, por transmissão } \\
\text { causa mortis de imóvel rural com área não } \\
\text { superior a } 25 \text { ha (vinte e cinco hectares), de } \\
\text { cuja exploração do solo depende o sustento } \\
\text { da família do herdeiro ou do cônjuge } \\
\text { supérstite a que tenha cabido partilha } \\
\text { desde que outro não possua; }\end{array}$ \\
\hline Pernambuco & $\begin{array}{l}\text { Lei } 13.974 \text { de } 16 \text { de } \\
\text { dezembro de } 2009 \text {, e } \\
\text { Lei } 15.601 \text { de } 30 \text { de } \\
\text { setembro de } 2015 .\end{array}$ & $8 \%$ & 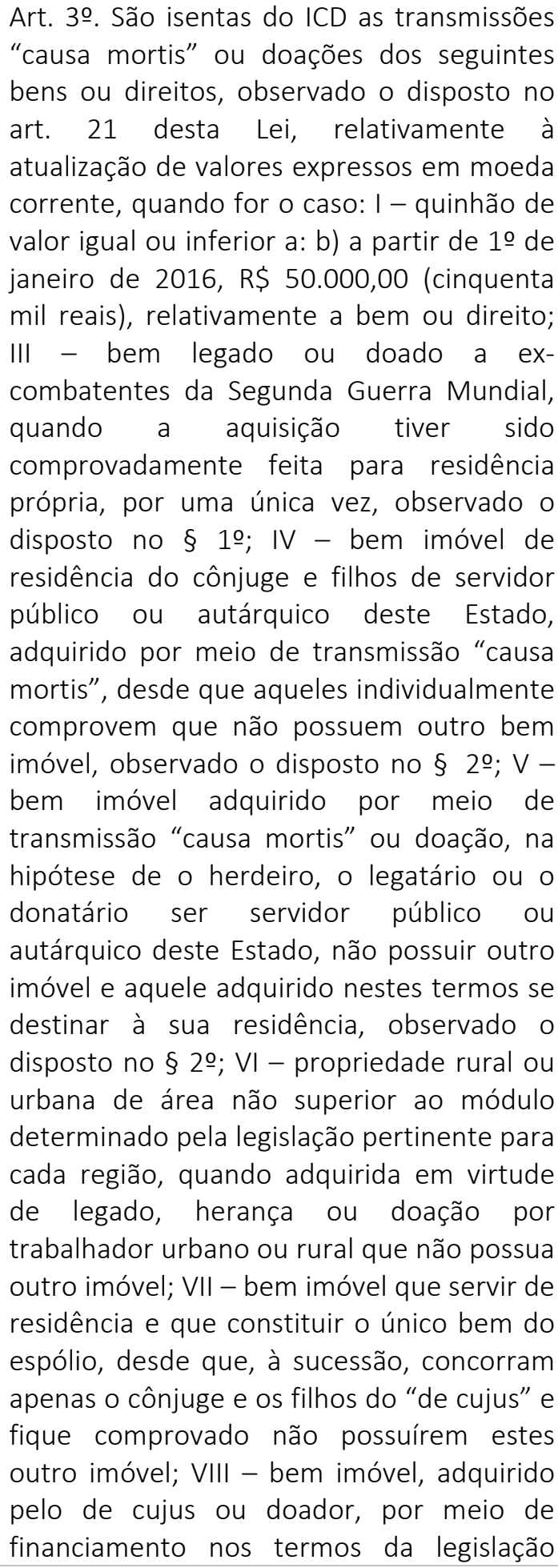 \\
\hline
\end{tabular}




\begin{tabular}{|c|c|c|c|}
\hline & & & $\begin{array}{l}\text { federal concernente ao Sistema Financeiro } \\
\text { de Habitação - SFH, bem como aquele } \\
\text { adquirido por meio da Companhia Estadual } \\
\text { de Habitação e Obras - CEHAB, de } \\
\text { cooperativa habitacional, de empresa } \\
\text { municipal de habitação e de empresa } \\
\text { integrante da Administração Pública } \\
\text { Indireta do Estado de Pernambuco, que } \\
\text { tenham como objeto social a participação } \\
\text { na política estadual de habitação, } \\
\text { observado o disposto no § 9o; § 9o. A partir } \\
\text { de } 1 \text { o de janeiro de } 2016 \text {, a isenção prevista } \\
\text { no inciso VIII do caput somente se aplica a } \\
\text { imóvel cujo valor não ultrapasse o limite de } \\
\text { R\$ 200.000,00 (duzentos mil reais). }\end{array}$ \\
\hline Piauí & $\begin{array}{l}\text { Lei Ordinária } 6.043 \text { de } \\
30 \text { de dezembro de } \\
2010 .\end{array}$ & $4 \%$ & $\begin{array}{l}\text { Art. } 8^{\circ} \text {. São isentas do imposto: I - a } \\
\text { transmissão causa mortis: a) de imóvel } \\
\text { urbano residencial, desde que sua avaliação } \\
\text { seja igual ou inferior a } 15.000 \text { (quinze mil) } \\
\text { Unidades Fiscais de Referência do Piauí - } \\
\text { UFR/PI e que este seja o único bem objeto } \\
\text { da partilha; b) de imóvel rural, cuja área não } \\
\text { ultrapasse o módulo rural da região, e } \\
\text { desde que o beneficiário não seja } \\
\text { proprietário de outro imóvel e não receba } \\
\text { mais do que um imóvel por ocasião da } \\
\text { transmissão; }\end{array}$ \\
\hline $\begin{array}{l}\text { Rio de } \\
\text { Janeiro }\end{array}$ & $\begin{array}{l}\text { Lei } 7.174 \text { de } 28 \text { de } \\
\text { dezembro } 2015 .\end{array}$ & $5 \%$ & $\begin{array}{l}\text { Art. 80. Estão isentas do imposto: VII - a } \\
\text { transmissão causa mortis de bens e direitos } \\
\text { integrantes de monte-mor cujo valor total } \\
\text { não ultrapasse a quantia equivalente a } \\
13.000 \text { (treze mil) Unidades Fiscais de } \\
\text { Referência do Estado do Rio de Janeiro } \\
\text { (UFIRs/RJ); XI - a transmissão causa mortis } \\
\text { de imóveis residenciais a pessoas físicas, } \\
\text { desde que a soma do valor dos mesmos não } \\
\text { ultrapasse o valor equivalente a } 100.000 \\
\text { (cem mil) UFIRs/RJ; XII - a transmissão } \\
\text { causa mortis de um único imóvel para } \\
\text { residência própria, por única vez, quando } \\
\text { feita a herdeiros necessários de policiais } \\
\text { militares e civis, e agentes penitenciários } \\
\text { mortos comprovadamente em decorrência } \\
\text { do desempenho da atividade profissional; } \\
\text { XIII - a transmissão causa mortis de imóveis } \\
\text { residenciais dos Programas de } \\
\text { Arrendamento Residencial (PAR) e Minha } \\
\text { Casa Minha Vida, observados os valores dos } \\
\text { respectivos programas; XIV - a transmissão }\end{array}$ \\
\hline
\end{tabular}




\begin{tabular}{|c|c|c|c|}
\hline & & & $\begin{array}{l}\text { causa mortis de imóveis localizados em } \\
\text { Unidades de Conservação da Natureza onde } \\
\text { os residentes pertençam à comunidades } \\
\text { tradicionais e quilombolas, devidamente } \\
\text { comprovados, na forma da legislação; }\end{array}$ \\
\hline $\begin{array}{c}\text { Rio Grande } \\
\text { do Norte }\end{array}$ & $\begin{array}{l}\text { Lei } 5.887 \text { de } 15 \text { de } \\
\text { fevereiro de } 1989 \text {, e } \\
\text { Lei } 9.993 \text { de } 29 \text { de } \\
\text { outubro de } 2015 .\end{array}$ & $6 \%$ & $\begin{array}{l}\text { Art. 3o. São isentas do imposto: II - os } \\
\text { legados e doações feitos a ex-combatentes } \\
\text { da Segunda Guerra Mundial, quando a } \\
\text { aquisição tiver sido comprovadamente feita } \\
\text { para residência própria, por uma única vez; } \\
\text { III - a transmissão "causa mortis" relativa a } \\
\text { bem imóvel de residência do cônjuge e } \\
\text { filhos do "de cujus" desde que } \\
\text { individualmente comprovem que não } \\
\text { possuem outro bem imóvel; IV - a } \\
\text { transmissão "causa mortis" e doação de } \\
\text { imóvel destinado à própria residência, na } \\
\text { hipótese de o herdeiro, o legatário ou o } \\
\text { donatário não possuir outro imóvel de } \\
\text { idêntica finalidade; } V \text { - a propriedade rural } \\
\text { ou urbana de área não superior ao módulo } \\
\text { determinado pela legislação pertinente para } \\
\text { cada região, quando for adquirida em } \\
\text { virtude de legado, herança ou doação por } \\
\text { trabalhador urbano ou rural que não possua } \\
\text { outro imóvel. }\end{array}$ \\
\hline $\begin{array}{c}\text { Rio Grande } \\
\text { do Sul }\end{array}$ & $\begin{array}{l}\text { Lei } 8.821 \text { de } 27 \text { de } \\
\text { janeiro de } 1989 \text {, Lei } \\
14.741 \text { de } 24 \text { de } \\
\text { setembro de } 2015 \text {, e } \\
\text { Decreto } 40.609, \text { de } \\
29 \text { de janeiro de } \\
2001 .\end{array}$ & $6 \%$ & $\begin{array}{l}\text { Art. 70. É isenta do imposto a transmissão: I } \\
\text { - de imóvel urbano, desde que seu valor } \\
\text { não ultrapasse o equivalente a } 4.379 \\
\text { (quatro mil trezentas e setenta e nove) } \\
\text { UPF/RS e o recebedor seja ascendente, } \\
\text { descendente ou cônjuge, ou a ele } \\
\text { equiparado, do transmitente, não seja } \\
\text { proprietário de outro imóvel e não receba } \\
\text { mais do que um imóvel, por ocasião da } \\
\text { transmissão; IV - de imóvel rural, desde que } \\
\text { o recebedor seja ascendente, descendente } \\
\text { ou cônjuge, ou a ele equiparado, do } \\
\text { transmitente, e, simultaneamente, não seja } \\
\text { proprietário de outro imóvel, não receba } \\
\text { mais do que um imóvel de até } 25 \text { (vinte e } \\
\text { cinco) hectares de terras por ocasião da } \\
\text { transmissão e cujo valor não ultrapasse o } \\
\text { equivalente a } 6.131 \text { (seis mil cento e trinta e } \\
\text { uma) UPF/RS; }\end{array}$ \\
\hline Rondônia & $\begin{array}{l}\text { Lei } 959 \text { de } 28 \text { de } \\
\text { dezembro de } 2000 \text {, e } \\
\text { Lei } 2.228 \text { de } 23 \text { de } \\
\text { dezembro de } 2009 \text {. }\end{array}$ & $4 \%$ & $\begin{array}{l}\text { Art. 6․ São isentos do pagamento do ITCD: I } \\
\text { - o herdeiro, o legatário ou o donatário que } \\
\text { houver recebido um único bem imóvel: a) } \\
\text { urbano, desde que, cumulativamente: } 1 .\end{array}$ \\
\hline
\end{tabular}




\begin{tabular}{|c|c|c|c|}
\hline & & & $\begin{array}{l}\text { seja edificado; } 2 \text {. seja destinado à moradia } \\
\text { própria ou de sua família; } 3 \text {. o beneficiário } \\
\text { não possua outro imóvel residencial; } 4 \text {. a } \\
\text { doação, a legação ou a participação na } \\
\text { herança limite-se a esse bem; e } 5 \text {. o valor } \\
\text { do bem seja igual ou inferior a } 1.250 \text { (um } \\
\text { mil, duzentas e cinquenta) UPF/RO. b) rural, } \\
\text { cuja área do imóvel recebido não ultrapasse } \\
60 \text { hectares; § 20. A isenção será concedida } \\
\text { ao herdeiro, legatário ou donatário } \\
\text { considerando-se o quinhão ou a parcela por } \\
\text { ele recebida, inclusive quando se tratar de } \\
\text { bem imóvel. }\end{array}$ \\
\hline Roraima & $\begin{array}{l}\text { Lei } 59 \text { de } 28 \text { de } \\
\text { dezembro de } 1993 .\end{array}$ & $4 \%$ & $\begin{array}{l}\text { Art. 76. São isentos do ITCD: II-os legados } \\
\text { e doações feitos a ex-combatentes da } \\
\text { Segunda Guerra Mundial, ex-guardas } \\
\text { territoriais do ex-Território Federal de } \\
\text { Roraima ou a seus filhos menores ou } \\
\text { incapazes, quando o imóvel tiver sido } \\
\text { comprovadamente adquirido para } \\
\text { residência própria, desde que não possua } \\
\text { outros imóveis e a isenção ocorra uma } \\
\text { única vez; V - a propriedade rural de área } \\
\text { não superior a } 60 \text { (sessenta) hectares, } \\
\text { quando for adquirida em virtude de legado, } \\
\text { herança ou doação, por trabalhador rural } \\
\text { que não possua outro imóvel urbano ou } \\
\text { rural; VI - os imóveis legados ou doados, } \\
\text { quando vinculados a programas } \\
\text { habitacionais de promoção social ou } \\
\text { desenvolvimento comunitário de âmbito } \\
\text { federal, estadual ou municipal, destinados a } \\
\text { pessoas de baixa renda que } \\
\text { comprovadamente não possuam outro } \\
\text { imóvel; e VII - a herança, legado ou doação, } \\
\text { cujo valor seja inferior a } 50 \text { UFERRS. }\end{array}$ \\
\hline $\begin{array}{l}\text { Santa } \\
\text { Catarina }\end{array}$ & $\begin{array}{l}\text { Lei } 13.136 \text { de } 25 \text { de } \\
\text { novembro de } 2004 \text {. }\end{array}$ & $8 \%$ & $\begin{array}{l}\text { Art. 10. São isentos do pagamento do } \\
\text { imposto: III - o herdeiro, o legatário ou o } \\
\text { donatário que houver sido aquinhoado com } \\
\text { um único bem imóvel, relativamente à } \\
\text { transmissão causa mortis ou à doação deste } \\
\text { bem, desde que cumulativamente: a) o } \\
\text { imóvel se destine à moradia própria do } \\
\text { beneficiário; b) o beneficiário não possua } \\
\text { qualquer outro bem imóvel; e c) o valor } \\
\text { total do imóvel não seja superior a R\$ } \\
20.000,00 \text { (vinte mil reais); }\end{array}$ \\
\hline São Paulo & $\begin{array}{l}\text { Lei } 10.705 \text { de } 28 \text { de } \\
\text { dezembro de } 2000 \text {, e }\end{array}$ & $4 \%$ & $\begin{array}{l}\text { Art. 6o. Fica isenta do imposto: I - a } \\
\text { transmissão "causa mortis": a) de imóvel de }\end{array}$ \\
\hline
\end{tabular}




\begin{tabular}{|c|c|c|c|}
\hline & $\begin{array}{l}\text { Lei } 10.992 \text { de } 21 \text { de } \\
\text { dezembro de } 2001 .\end{array}$ & & $\begin{array}{l}\text { residência, urbano ou rural, cujo valor não } \\
\text { ultrapassar } 5.000 \text { (cinco mil) Unidades } \\
\text { Fiscais do Estado de São Paulo - UFESPs e } \\
\text { os familiares beneficiados nele residam e } \\
\text { não tenham outro imóvel; b) de imóvel cujo } \\
\text { valor não ultrapassar } 2.500 \text { (duas mil e } \\
\text { quinhentas) UFESPs, desde que seja o único } \\
\text { transmitido; }\end{array}$ \\
\hline Sergipe & $\begin{array}{l}\text { Lei } 7.724 \text { de } 08 \text { de } \\
\text { novembro de } 2013 \text {, e } \\
\text { Lei } 8.044 \text { de } 10 \text { de } \\
\text { outubro de } 2015 \text {. }\end{array}$ & $8 \%$ & $\begin{array}{l}\text { Art. 8o. São isentos do imposto: I - as } \\
\text { transmissões "causa mortis" ou por doação } \\
\text { de imóveis a colonos em núcleos oficiais ou } \\
\text { reconhecidos pelo Governo, em } \\
\text { atendimento à política de redistribuição de } \\
\text { terras; II - as transmissões "causa mortis" } \\
\text { de imóvel rural de área não superior ao } \\
\text { módulo rural, assim caracterizado na forma } \\
\text { da legislação pertinente, desde que feitas a } \\
\text { quem seja trabalhador rural e que não seja } \\
\text { proprietário ou possuidor de imóvel; VI - as } \\
\text { transmissões "causa mortis" de prédio de } \\
\text { residência que constitua o único bem } \\
\text { imóvel do espólio, desde que o valor seja } \\
\text { igual ou inferior a } 1.500 \text { (um mil e } \\
\text { quinhentas) UFP/SE, e cujos sucessores } \\
\text { comprovem não possuir outro imóvel. }\end{array}$ \\
\hline Tocantins & $\begin{array}{l}\text { Lei } 1.287 \text { de } 28 \text { de } \\
\text { dezembro de } 2001 \text {, e } \\
\text { Lei } 3.019 \text { de } 30 \text { de } \\
\text { setembro de } 2015 \text {. }\end{array}$ & $8 \%$ & $\begin{array}{l}\text { Art. 55. É isento do pagamento do ITCD: I- } \\
\text { o herdeiro ou legatário, que receber } \\
\text { quinhão ou legado, cujo valor seja igual ou } \\
\text { inferior a } \mathrm{R} \$ 25.000,00 \text {; }\end{array}$ \\
\hline
\end{tabular}

Fonte: Os autores (2017)

A análise do quadro acima permite verificar a grande disparidade existente entre as legislações estaduais sobe o ITCD, havendo unidades que consideram a força normativa do direito social à moradia e outras que a ignoram. Assim, tem-se o exemplo de uma unidade federativa em que não há previsão de isenção do imposto para famílias carentes, baseada no direito social à moradia. Caso do Alagoas. E também, no extremo oposto, exemplos de unidades federativas em que consta a previsão de que estão isentas de ITCD as heranças compostas de imóveis integrantes de "programas habitacionais de promoção social ou desenvolvimento comunitário de âmbito federal, estadual ou municipal, destinados a pessoas de baixa renda que comprovadamente não possuam outro imóvel", como em Roraima; e "dos Programas de Arrendamento Residencial (PAR) e Minha Casa Minha Vida, observados os valores dos respectivos programas", como no Rio de Janeiro. 
Entende-se que as duas últimas previsões descritas são as que melhor se aproximam do conteúdo eficacial mínimo do direito social à moradia, sob a ótica negativa. Com efeito, sendo dever do Estado a promoção de programas de moradia e a melhoria das condições habitacionais, o que é previsto como competência material comum da União, dos Estados, do Distrito Federal e dos Municípios, a ser seguido, pois, por todos os entes federativos, não faz sentido um ente federativo dar, para que outro ente federativo tome o imóvel, por meio da tributação. Por isso, considera-se que, em aplicação direta do direito social fundamental à moradia - mesmo para os Estados em que não haja semelhante previsão legal -, é possível ao Judiciário excluir da tributação do ITCD os imóveis cujos valores correspondam àqueles dos bens de raiz atribuídos em programas federais, estaduais ou municipais (considerado o efetivo estado ou município de situação dos bens), às famílias de baixa renda.

\section{CONSIDERAÇÕES FINAIS}

A eficácia é conceito jurídico complexo, que abrange tanto a denominada "eficácia social" ou efetividade, relacionada à efetiva aplicação da norma; quanto à chamada "eficácia jurídica" ou aplicabilidade, relativa à aptidão jurídica para produção de efeitos. A partir desse conceito, afirmou-se que o termo eficácia, utilizado neste trabalho, refere-se à eficácia jurídica.

Afirmou-se também que, embora a Constituição Federal estabeleça a aplicação imediata dos direitos fundamentais nela previstos, alguns direitos, como os sociais, encontram certos empecilhos para sua efetivação. Entre os mencionados entraves destacou-se a vagueza dos textos que os estabelecem e a falta de uma prática institucional de aplicação.

Destacou-se, porém, que tais direitos, por serem assim considerados pela Constituição, não podem ser examinados como se fossem simples intenções. Por essa razão, é indispensável determinar seu conteúdo de eficácia jurídica.

Todos os direitos possuem custos, embora os gastos relacionados aos direitos sociais sejam mais relevantes. Assim, verificou-se a dificuldade em se delimitar seu conteúdo eficacial mínimo sob a ótica prestacional, sobretudo, em razão da necessidade de universalização. Por outro lado, afirmou-se que essas mesmas dificuldades não se impõem sob o viés negativo dos direitos sociais, que exigem simples abstenções do Estado.

Viu-se, ainda, que o direito à moradia foi capitulado como um dos direitos fundamentais de caráter social pelo constituinte pátrio, bem como por órgãos internacionais. 
Afirmou-se, então, que as mesmas ponderações realizadas sobre a eficácia dos direitos sociais em geral se aplicam ao direito à moradia.

Em seguida, passou-se a analisar o papel da tributação no Estado contemporâneo. Nesse campo, afirmou-se que os tributos são instrumentos indispensáveis para a efetivação do Estado Social.

Destacou-se que, sendo função do Estado a garantia dos direitos fundamentais, e considerando-se que todo direito tem um custo, seria necessário assegurar ao Estado recursos suficientes para fazer frente às suas obrigações constitucionais. De outra parte, como o tributo é a forma de receita essencial do Estado, afirmou-se ser por meio de sua arrecadação que se possibilita a efetivação dos direitos fundamentais.

No entanto, a tributação também possui outro tipo de relação com os direitos fundamentais, já que, por vezes, é responsável por suprimir os recursos indispensáveis para cobrir as necessidades básicas do indivíduo. Por isso foi afirmado que os direitos fundamentais não são apenas o escopo, mas também funcionam como limites à tributação.

Viu-se que a instituição e cobrança do ITCD é competência dos Estados e do Distrito Federal. Passou-se, assim, a analisar a "regra-matriz" ou "norma-padrão de incidência" do imposto.

Em linhas gerais, o critério material é a transmissão decorrente da morte; o critério temporal é determinado pela data da ocorrência do óbito; e o critério espacial do imposto é definido pela Constituição, sendo competente para sua cobrança, no que se refere aos bens imóveis, o Estado da situação do bem ou o Distrito Federal. O sujeito passivo é o herdeiro, legatário ou cessionário da herança, após sua aceitação; a base de cálculo é o valor venal do bem; e a alíquota máxima, tal como definida pelo Senado Federal, é de $8 \%$, aplicando-se a fixada pela legislação local, desde que observado o limite mencionado.

Após o exame das regras gerais sobre o imposto, apresentou-se a legislação de cada uma das vinte e sete unidades federativas, no que concerne à alíquota máxima aplicada em seu território; e também à eventual previsão de norma de isenção do imposto em prol de famílias carentes. Constatou-se, dessarte, a grande disparidade existente entre as legislações.

Concluiu-se que, em decorrência da eficácia do direito social à moradia, sob seu viés negativo, mesmo nos Estados em que não exista semelhante previsão, é possível ao Judiciário afastar a incidência do ITCD quanto aos imóveis de valor compreendido em programa habitacional, destinado a pessoas de baixa renda, de qualquer das esferas (federal, estadual ou municipal). Isso porque não faz sentido permitir que um ente dê e o outro tire o imóvel por 
meio da tributação, até mesmo porque a Constituição Federal estabeleceu a promoção da moradia como competência material comum.

\section{REFERÊNCIAS}

ABRAMOVICH, Víctor; COURTIS, Christian. Los derechos sociales como derechos exigibles. Madrid: Editorial Trotta, 2002.

BARROSO, Luís Roberto. A efetividade das normas constitucionais revisitada. R. Dir. Proc. Geral, Rio de Janeiro, (48), pp. 60-98, 1995. Disponível em: $<$ https://www.pge.rj.gov.br/comum/code/MostrarArquivo.php?C=MjAxNw\%2C\%2C>. Acesso em: 10 dez. 2016.

BOBBIO, Norberto. Teoria da norma jurídica. Trad. Fernando Pavan Baptista e Ariani Bueno Sudatti. Bauru - SP: EDIPRO, 2001.

BRASIL. Supremo Tribunal Federal. Medida Cautelar em Arguição de Descumprimento de Preceito Fundamental 45/DF. ARGTE.: Partido da Social Democracia Brasileira - PSDB. ARGDO.: Presidente da República. Relator: Celso de Mello. Brasília, 29 de abril de 2004. Diário da Justiça de 04.05.2004, pp. 00012.

BRASIL, Senado Federal. Resolução 9 de 1992. Estabelece alíquota máxima para o Imposto sobre Transmissão Causa Mortis e Doação, de que trata a alínea a, inciso I, e § 1으, inciso IV do art. 155 da Constituição Federal. Brasília, DF. Diário Oficial da União de 06/05/1992, p. 178.

BRASIL. Supremo Tribunal Federal. Súmula 114. Súmula da Jurisprudência Predominante do Supremo Tribunal Federal - Anexo ao Regimento Interno. Edição: Imprensa Nacional, 1964, p. 71.

BRASIL. Supremo Tribunal Federal. Súmula 331. Súmula da Jurisprudência Predominante do Supremo Tribunal Federal - Anexo ao Regimento Interno. Edição: Imprensa Nacional, 1964, p. 146.

CARMONA, Paulo Afonso Cavichioli. A tutela do direito de moradia e o ativismo judicial. In: Revista Brasileira de Políticas Públicas. ISSN 2236-1677. Brasília, v. 5, Número Especial, pp. 264289, $2015 . \quad$ Disponível em: <https://www.publicacoesacademicas.uniceub.br/RBPP/article/view/3075/pdf>. Acesso em: 15 dez. 2016.

CARVALHO, Paulo de Barros. Direito tributário: linguagem e método. 5a ed. São Paulo: Noeses, 2013.

CORTI, Horácio G. Derechos Fundamentales y presupuesto público: uma renovada relación em el marco del neoconstitucionalismo periférico. In: CONTI, José Maurício; SCAFF, Fernando Facury (Coord.). Orçamentos públicos e direito financeiro. São Paulo: Revista dos Tribunais, 2011. 
ESTEVAN, Juan Manuel Barquero. La función del tributo en el Estado social y democrático de Derecho. Madrid: Centro de Estudios Políticos y Constitucionales, 2002.

GASSEN, Valcir; D’ARAÚJO, Pedro Júlio Sales; PAULINO, Sandra Regina da F. Tributação sobre Consumo: o esforço em onerar mais quem ganha menos, Sequência, Florianópolis, N. 66, p. 213-234, 2013. Disponível em: <http://www.scielo.br/pdf/seq/n66/09.pdf>. Acesso em: 18 dez. 2016.

GOTTI, Alessandra. Direitos sociais: fundamentos, regime jurídico, implementação e aferição de resultados. São Paulo: Saraiva, 2012.

HOLMES, Stephen; SUNSTEIN, Cass R. The cost of rights: why liberty depends on taxes. New York: W. W. Norron \& Company, 1999.

MEIRA, Liziane Angelotti. Direitos fundamentais e tributação: saúde, salário, aposentadoria e tributação - tensão dialética? In: BRANCO, Paulo Gonet; MEIRA, Liziane Angelotti; CORREIA NETO, Celso de Barros (Coord.). Tributação e direitos fundamentais: conforme a jurisprudência do STF e do STJ. São Paulo: Saraiva, 2012.

MELLO, Celso Antônio Bandeira de. O Conteúdo Jurídico do Princípio da Igualdade. $3^{a}$ ed. São Paulo: Malheiros, 2001.

NABAIS, José Casalta. O dever fundamental de pagar impostos. Coimbra: Livraria Almedina, 1998.

OLIVEIRA, Alexandre Machado de; BORGES, Antônio de Moura. Limitações ao princípio da capacidade contributiva: mínimo existencial e confisco. In: CONPEDI Law Review. Uruguai, v. 2, n. 4, pp. 180-200, jul./dez. $2016 . \quad$ Disponível em: <http://portaltutor.com/index.php/conpedireview/article/view/367/367>. Acesso em: 20 jun. 2017.

REALE, Miguel. Lições preliminares de direito. 27ạ ed. São Paulo: Saraiva, 2002.

SARLET, Ingo Wolfgang. A eficácia dos direitos fundamentais: uma teoria geral dos direitos fundamentais na perspectiva constitucional. 12a ed. Porto Alegre: Livraria do Advogado Editora, 2015.

SCHOUERI, Luís Eduardo. Tributação e liberdade. In: PIRES, Adilson Rodrigues; TÔRRES, Heleno Taveira (Org.). Princípios de direito financeiro e tributário: estudos em homenagem ao professor Ricardo Lobo Torres. Rio de Janeiro: Renovar, 2006.

SILVA, José Afonso da. Aplicabilidade das normas constitucionais. 3ạ ed. São Paulo: Malheiros, 1998.

SILVA, José Afonso da. Curso de direito constitucional positivo. 25a ed. São Paulo: Malheiros, 2005.

SILVA, Virgílio Afonso da. O Judiciário e as políticas públicas: entre transformação social e obstáculo à realização dos direitos sociais. In: SOUZA NETO, Cláudio Pereira de; SARMENTO, 
Daniel (Coord.). Direitos sociais: fundamentação, judicialização e direitos sociais em espécies. Rio de Janeiro: Lumen Juris, 2008.

SOUZA NETO, Cláudio Pereira de. A Justiciabilidade dos Direitos Sociais: Críticas e Parâmetros. In: SOUZA NETO, Cláudio Pereira de; SARMENTO, Daniel (Coord.). Direitos Sociais: Fundamentos, Judicialização e Direitos Sociais em Espécie, Rio de Janeiro: Lumen Juris, 2008.

VILANOVA, Lourival. Fundamentos do Estado de Direito. In: Revista do Instituto dos Advogados Brasileiros. Ano XII, n. 54, pp. 65-80, 1o semestre de 1978.

Trabalho enviado em 22 de novembro de 2017.

Aceito em 07 de março de 2018. 